\title{
Aspectos Motivacionais na Disciplina de Cálculo Diferencial e Integral
}

\author{
Odileia da Silva Rosa \\ Universidade Severino Sombra, CECETEN, Departamento de \\ Matemática, odileia.dasilvarosa@gmail.com \\ Chang Kuo Rodrigues \\ Universidade Severino Sombra, CECETEN, Mestrado Profissional em \\ Educação Matemática, chang@powerline.com.br \\ Patrícia Nunes da Silva \\ Universidade do Estado do Rio de Janeiro, Departamento de \\ Matemática, patnsilva@gmail.com
}

\begin{abstract}
Resumo: Neste trabalho, investigamos a motivação e o uso de estratégias de aprendizagem como um fator que influencia o aprendizado em Cálculo Diferencial e Integral. Buscamos traçar um perfil motivacional de turmas da referida disciplina nos cursos de Engenharia Ambiental, Engenharia Elétrica e Matemática em duas diferentes instituições de ensino superior, uma pública e outra privada. Utilizamos como ferramenta para levantamento de dados uma adaptação do Motivated Strategies for Learning Questionnaire (MSLQ). Aplicamos os questionários em dois momentos, no início e no final do semestre. Os dados da primeira aplicação nos permitiram traçar o perfil motivacional da turma, servindo de parâmetro para, na segunda aplicação, verificarmos o impacto do primeiro contato dos alunos com a disciplina de Cálculo Diferencial e Integral. Diante dos resultados, após o levantamento do perfil das turmas citadas, nos foi possivel apontar algumas ações a serem desenvolvidas tanto para o professor como para cada turma envolvida em nossa investigação. Assim, a nossa pretensão, apesar de simples, pode servir como mais um meio de contribuição na área de Educação Matemática, focada essencialmente em prol do processo de ensino e de aprendizagem na Matemática.
\end{abstract}

Palavras-chave: Cálculo diferencial e integral. Motivação. Estratégias de aprendizagem. MSLQ. Psicologia cognitiva.

\section{Motivational Aspects at the Discipline of Differential and Integral Calculus}

\begin{abstract}
In this paper we investigate the use of motivation and learning strategies as a factor influencing learning in Differential and Integral Calculus. We seek to profile classes of motivational classes on Environmental Engineering, Electrical
\end{abstract}




\begin{abstract}
Engineering and Mathematics in two different higher education institutions, a public one and a private one. We used as a tool for data collection an adaptation of the Motivated Strategies for Learning Questionnaire (MSLQ). We apply the questionnaires at two stages, at the beginning and end of the semester. Data from the first application enabled us to trace the motivational profile of the group, serving as a parameter to the second application and verify the impact of students' first contact with Differential and Integral Calculus. Considering the results, after lifting the profile of the groups mentioned above, we could point out some actions to be developed by both the teacher and each class member involved in our investigation. So our claim, albeit simple, can serve as an additional contribution to the field of mathematics education, focusing primarily on teaching and learning mathematics.
\end{abstract}

Keywords: Differential and integral calculus. Motivation. Learning strategies. MSLQ. Cognitive psychology.

\title{
Introdução
}

O Cálculo Diferencial e Integral (CDI) está presente em todas as matrizes curriculares dos cursos de graduação em Ciências Exatas. Em geral, é lecionado em disciplinas nos semestres iniciais dos cursos. $\mathrm{O}$ alto índice de reprovação verificado nessas disciplinas nas diversas Instituições de Ensino, tanto público como privado, colocam o Cálculo Diferencial e Integral no centro de discussões e pesquisas acadêmicas.

De um modo geral, as pesquisas relacionadas ao CDI têm em comum o fato de centraremse nos aspectos do insucesso, das dificuldades, da desmotivação. Neste trabalho adotamos uma perspectiva ligeiramente diferente. Queremos identificar as motivações e estratégias de estudo e aprendizagem que o estudante traz, ou trazia, no primeiro contato com a disciplina. Portanto, o nosso objeto de pesquisa é a disciplina de Cálculo Diferencial e Integral em cursos de graduação nas modalidades bacharelado e licenciatura. Levantaremos aspectos motivacionais e estratégias de aprendizagens de estudantes da disciplina de CDI, a fim de fornecer aos professores e aos estudantes da disciplina subsídios que permitam potencializar ou redirecionar esses parâmetros, partindo do pressuposto de que os estudantes necessariamente são sujeitos que atuam por uma aprendizagem provida de significados.

Nesse sentido, acreditamos que para um estudante ser bem-sucedido precisa assumir a condução de seu processo de aprendizagem e utilizar, de forma ativa, estratégias para gerenciar a motivação, seu comportamento e sua aprendizagem. Além disso, deve, continuamente, ser capaz de refletir suas ações, avaliá-las e fazer as devidas correções, quando necessário. Em síntese, deve desenvolver a habilidade de aprender a aprender.

Nas duas últimas décadas, ressurgiu o interesse pelo estudo de aspectos motivacionais e, em especial, no que diz respeito à compreensão do efeito da motivação sobre a cognição e a aprendizagem. Há uma intensa atividade de pesquisas psicológicas sobre motivação aplicada em diferentes contextos educacionais. Por isso, a pertinência desse tema tomado como objeto de nosso estudo.

Os altos índices de reprovação na disciplina CDI, por si só, exigem uma reflexão tanto sobre 
suas causas como sobre possíveis estratégias de reversão desse quadro. A investigação de aspectos motivacionais e de estratégias de aprendizagem de estudantes de CDI pode abrir novas perspectivas e contribuir para a compreensão da dinâmica dos processos de ensino e de aprendizagem nessa disciplina. Esse tipo de pesquisa, em qualquer disciplina, é recente e mostra-se bastante relevante na eficácia do aprendizado do aluno.

\section{Aspectos Motivacionais e Estratégias de Aprendizagem}

Nossa pesquisa se apoia em uma visão cognitiva geral e social da motivação e das estratégias de aprendizagem. Nos últimos anos, essas teorias ganharam força e espaço no contexto de ensino e de aprendizagem e têm-se mostrado úteis na compreensão dos mecanismos que regulam o comportamento dos estudantes. Assim, discutiremos alguns pontos acerca da Psicologia Cognitiva e Psicologia Social Cognitiva.

\section{Motivação}

Nas abordagens cognitivas, a motivação é entendida como um conjunto de processos complexos e multideterminados que regulam a ativação, a direção e a persistência. No contexto escolar, as abordagens cognitivas entendem que a inteligência e a capacidade intelectual não são suficientes para explicar o sucesso ou o fracasso escolar do estudante. A motivação é considerada um dos principais fatores que favorecem o aprendizado do estudante e também um determinante crítico do nível da qualidade da aprendizagem e de seu desempenho. A motivação inadequada ou a falta de motivação pode gerar rendimentos inferiores às suas (dos estudantes) capacidades e potencialidades (Guimarães, 2003; Zenorini, 2007).

\section{Estratégias de Aprendizagem}

As estratégias de aprendizagem são ações mentais e comportamentais cujo objetivo é melhorar o desempenho nas atividades acadêmicas. São facilitadoras dos processos cognitivos de codificação, aquisição e processamento de informações. (Machado, 2005). São classificadas em cognitivas, metacognitivas e de gerenciamento de recursos. As cognitivas estão relacionadas diretamente com a execução de tarefas. Referem-se a comportamentos e aos processos mentais que favorecem o armazenamento eficiente da informação. $\mathrm{O}$ uso adequado de estratégias cognitivas promove o chamado processamento da informação em nível profundo, em oposição às formas de processamento de superfície. As estratégias cognitivas se dividem em três tipos: as técnicas (de repetição, de memorização), as de elaboração e as de organização. As metacognitivas, por sua vez, referem-se à consciência e ao conhecimento desses processos mentais por parte de quem os usa. Correspondem a procedimentos usados para planejar, avaliar, monitorar e regular o uso das estratégias e processos cognitivos. As estratégias de gerenciamento de recursos se referem a como os estudantes administram os fatores associados ao ato de estudar em si, como planejamento do tempo disponível e escolha de um ambiente adequado para os estudos e também o esforço necessário para a realização de determinada tarefa (Bartalo, 2006; Machado, 2005; Souza, 2010). 
Várias pesquisas apontam que a motivação associada a estratégias de aprendizagens adequadas pode garantir bons resultados acadêmicos. E, nesse sentido, torna-se necessário ensinar e incentivar os estudantes a usarem estratégias de estudo e aprendizagem para que conheçam as estratégias adequadas, façam uso delas e compreendam quais são os seus benefícios e como funcionam. As estratégias de aprendizagem, diferentemente dos constructos motivacionais, não são características inatas; por este motivo é necessário que seu uso seja incentivado. (Bartalo, 2006; Ruiz, 2005; Machado, 2005).

\section{Motivated Strategies for Learning Questionnaire (MSLQ)}

O Motivated Strategies for Learning Questionnaire (Questionário de Estratégias Motivadas de Aprendizagem) é um instrumento de autorrelato criado para ter acesso às orientações motivacionais de estudantes universitários e ao uso que fazem de estratégias de aprendizagem relativas a uma determinada disciplina de graduação. (McKeachie, Pintrich, Lin \& Smith, 1986; Pintrich, 1991). Contempla três escalas de constructos de motivação: componente Valor (subdividida em orientação para a meta intrínseca, orientação para a meta extrínseca e crenças sobre o valor das tarefas); a Expectativa (subdividida em percepção de autoeficácia e as crenças sobre controle da aprendizagem) e Afeto. Além disso, o MSLQ, também contempla três escalas relativas às estratégias de aprendizagem: Cognitivas, Metacognitivas e Gerenciamento de recursos (tempo, esforço etc.).

Os modelos teóricos que subsidiam a concepção do MSLQ são: Teoria de Metas de Realização, Teoria da Autodeterminação e Expectativa-Valor. A primeira focaliza as razões que movem os alunos ou os objetivos a que perseguem quando aprendem. A segunda distingue as pessoas em função do nível e do tipo de motivação que apresentam. Considera, basicamente, as motivações: intrínseca e extrínseca. Por sua vez, a teoria Expectativa-Valor acrescenta às razões ou objetivos que mobilizam um estudante e à crença em sua capacidade de êxito, a importância do valor da tarefa como mais um componente que influencia seu comportamento (Guimarães, 2003; Locatelli, 2004; Ruiz, 2005; Zenorini, 2007).

O constructo principal envolvido na Teoria de Metas de Realização é o de orientação para meta e se refere ao aspecto qualitativo do envolvimento do estudante. As metas são representadas por maneiras distintas de enfrentar as tarefas acadêmicas. A orientação para Meta Intrínseca refere-se ao grau de percepção que o estudante tem de que as razões de sua participação na tarefa sejam devido ao desafio e à curiosidade. A orientação para Meta Extrínseca está relacionada ao grau de percepção que se tem acerca das razões de sua participação na tarefa, sejam devido às notas, recompensas, performance, avaliação dos outros e/ou competição (Pintrich, 1991; Ruiz, 2005; Zenorini, 2007).

Um estudante que apresenta orientação para meta intrínseca em relação a uma tarefa acadêmica participa da tarefa como um fim em si mesmo, muito mais do que um meio para outro fim. O fracasso é considerado inerente ao processo de aprendizagem. Por outro lado, quando um estudante tem alta orientação para meta extrínseca, empenhar-se em uma tarefa é um meio para um fim. A maior preocupação do estudante está relacionada aos aspectos não diretamente associados à tarefa propriamente dita, (como notas, recompensas, comparação com o desempenho de outros). Atribui o fracasso à falta de capacidade. (Pintrich et al, 1991; Ruiz, 2005). 
A Teoria de Autodeterminação está voltada para compreender questões sobre a motivação e aborda a personalidade e a motivação humanas. Nesta teoria, as pessoas diferem-se em relação ao nível e ao tipo de motivação. Dela distinguem-se questões motivacionais de o porquê para o quê. Dois tipos de motivação são propostos: a motivação intrínseca, na qual a atividade é o fim em si mesmo e a motivação extrínseca, cujo envolvimento na atividade é um meio para obter resultados externos. (Lens et al., 2008; Machado, 2005; Zenorini, 2007).

A Teoria Expectativa-Valor enfatiza que a aprendizagem é influenciada, não apenas pelas metas específicas da tarefa e pelas crenças quanto ao êxito, mas também pela importância dada ao conteúdo. Nessa teoria, a motivação seria determinada por aquilo que a pessoa espera obter e a possibilidade de consegui-lo (Guimarães, 2003; Locatelli, 2004). Pintrich (1991) e seus colaboradores acrescentaram o componente afetivo ao modelo ExpectativaValor. A componente expectativa representa as crenças da pessoa quanto à sua capacidade de realizar uma tarefa. Esta componente está associada aos estudos que dizem respeito às crenças de autoeficácia, percepção de competência, crenças atribucionais e de controle. $\mathrm{O}$ componente valor é caracterizado pelas diferentes metas dos estudantes e as crenças sobre a importância e o interesse da tarefa. O componente afetivo inclui as reações emocionais dos estudantes às tarefas acadêmicas ou aos resultados de seu desempenho (Genari, 2006; Guimarães, 2003; Pintrich et al., 1991; Ruiz, 2005).

\section{Metodologia}

Os questionários foram aplicados aos estudantes dos cursos de Engenharia Ambiental e Engenharia Elétrica de uma instituição de ensino superior privada e em estudantes do curso de Matemática de uma universidade pública, matriculados na disciplina Cálculo Diferencial e Integral. A participação foi voluntária e sem identificação e durou cerca de 20 minutos. Foram analisados somente os questionários que não apresentavam resposta em branco. Os estudantes presentes na sala de aula responderam ao questionário em duas ocasiões: no início do segundo semestre de 2010 e ao seu final, em ambas as instituições.

Na Engenharia Ambiental, 35 estudantes responderam ao questionário, no início do semestre, sendo computados apenas 31, pois 4 apresentavam respostas em branco; 21 foram respondidos ao final do semestre.

Dos 34 questionários respondidos pelos estudantes de Engenharia Elétrica no início do semestre, foram computados apenas 27, pois 7 apresentavam respostas em branco. Somente 22 responderam ao questionário ao final do semestre.

Dos 30 estudantes do curso de Matemática da instituição pública que responderam ao questionário no início do semestre, apenas 28 foram computados, pois 2 apresentaram respostas em branco; 20 responderam ao questionário no final do semestre, sendo computados apenas 18, pois 2 também apresentaram respostas em branco.

Apresentamos a análise descritiva dos dados da primeira e da segunda aplicação do questionário. Posteriormente, fizemos outra análise, o que nos proporcionou fazer um paralelo entre os dois resultados. Os procedimentos quantitativos utilizaram as seguintes medidas: médias aritméticas, medianas, quartis e extremos (maior e menor valores), e aplicamos a análise correlacional dos dados, utilizando o método de Spearman. 


\section{Ferramenta de Análise}

Nossa ferramenta de análise foi um questionário composto de 54 questões propostas, seguindo o modelo da escala Likert de sete pontos, a partir de 1 (nada verdadeiro para mim) até 7 (muito verdadeiro para mim) (ROSA, 2011). As questões foram adaptadas do MSLQ. Elas contemplam as três escalas de construtos de motivação do MSLQ: a componente Valor (subdividida em orientação para a meta intrínseca, orientação para a meta extrínseca e crenças sobre o valor das tarefas); a Expectativa (subdividida em percepção de autoeficácia e as crenças sobre controle da aprendizagem); e a Afeto. Além disso, as questões também contemplam as duas escalas relativas às estratégias de aprendizagem: das estratégias cognitivas e metacognitivas e da utilização de recursos (tempo, esforço etc.).

A escala Valor está subdividida em orientação para meta intrínseca, orientação para meta extrínseca e crenças sobre o valor da tarefa. A orientação para meta indica o porquê de o estudante se empenhar na tarefa, e as crenças sobre o valor da tarefa referemse à avaliação do estudante sobre quão interessante, importante e útil é a tarefa. Os itens extraídos de nosso questionário, e apresentados a seguir, ilustram esses aspectos: 1. Nas aulas de Cálculo I, eu prefiro conteúdos que realmente me desafiem, de maneira que eu possa aprender coisas novas; 5. Obter boas notas neste curso é o que me dará maior satisfação neste momento; 8. É importante para mim, aprender o conteúdo desta disciplina.

A escala Expectativa está subdivida em percepção de autoeficácia e crenças de controle da aprendizagem. As crenças de controle da aprendizagem dizem respeito às crenças do estudante de que seus esforços para aprender terão resultados positivos. O controle da aprendizagem se refere à crença de que os resultados obtidos são dependentes do esforço pessoal e não de fatores externos como o do professor, por exemplo. Ao acreditar que seus esforços de estudo podem fazer diferença em seu aprendizado, os estudantes ficam propensos a estudar mais estrategicamente e de modo mais efetivo. A autoeficácia é a autoavaliação que cada um tem de sua própria habilidade em cumprir ou resolver uma tarefa. A autoeficácia inclui julgamentos sobre a própria habilidade de concluir uma tarefa bem como sobre a confiança que cada um deposita em sua capacidade de cumpri-la.

A escala Expectativa captura a compreensão que o estudante tem de que seu desempenho depende de seu esforço, que percepções que tem de sua aptidão e capacidade para realizar as tarefas, bem como que resultados espera alcançar. Para ilustrar estes componentes, extraímos os seguintes itens de nosso questionário 2. Se eu estudar de forma adequada, então serei capaz de aprender o conteúdo desta disciplina; 10. Estou confiante que posso aprender os conteúdos básicos ensinados no curso; 21. Considerando a dificuldade do curso, os professores e minha competência, eu acho que me sairei bem neste curso.

A escala Afeto é analisada na subescala ansiedade frente a provas. Esta escala captura as inquietações (componente cognitivo) e reações emocionais (componente emocional) suscitadas pelas tarefas. Em nosso questionário, os dois itens associam-se à seguinte escala, a saber: 12. Quando eu pego as provas penso nas consequências de me sair mal; 19. Eu sinto meu coração acelerar quando pego uma prova.

As questões apresentadas em nosso questionário referentes à escala Cognitiva das 
estratégias de aprendizagem correspondem a estratégias de elaboração e organização. As estratégias Metacognitivas são analisadas na subescala metacognição e autorregulação. Finalmente, as estratégias de Gerenciamento de recursos são avaliadas nas subescalas de gerenciamento do tempo, regulação do esforço e busca por ajuda.

Dentre as Cognitivas, as estratégias de elaboração ajudam o estudante a armazenar informação na memória de longo prazo por meio da construção de conexões internas entre os itens a serem aprendidos. Essas estratégias incluem paráfrase, resumos, analogias e anotações. As de organização, por sua vez, ajudam o estudante a selecionar informações adequadas e também a estabelecer conexões internas ao conteúdo a ser aprendido. Exemplos de estratégias de organização são agrupar, esquematizar, identificar a ideia principal de trechos durante a leitura.

O MSLQ considera três processos gerais que compõem as atividades metacognitivas autorregulatórias: atividades de planejamento, como as de traçar metas e analisar a tarefa, o que ajuda a ativar aspectos relevantes do conhecimento prévio que facilitem a organização e a compreensão do material; atividades de monitoramento, que incluem manter a atenção enquanto se lê e fazer perguntas, o que ajuda o estudante a compreender o material e conectar com o conhecimento prévio; as atividades de regulação melhoram o desempenho ao ajudá-lo a checar e corrigir seu comportamento enquanto realiza uma tarefa.

As questões selecionadas de nosso questionário ilustram a escala Cognitiva das estratégias de aprendizagem: 41. Quando estudo para esta disciplina eu tento relacionar seu conteúdo com o que já sei. 28. Quando eu estudo para esta disciplina, uso os livros e as anotações feitas em sala de aula e tento identificar as ideias mais importantes; a Metacognitiva: 35. Eu faço perguntas para mim mesmo para ter certeza de que entendi o que foi apresentado em sala; e a de Gerenciamento de recursos: 33. Eu tenho dificuldade para cumprir meus horários de estudo. 48. Mesmo quando o conteúdo é entediante e pouco interessante eu sou capaz de continuar trabalhando até que eu termine. 49. Eu tento identificar estudantes na classe a quem eu possa pedir ajuda se necessário.

Em síntese, ilustramos, no Quadro 1, as escalas e subescalas de constructos do MSLQ contidas em nosso questionário:

Quadro 1 - Escalas e subescalas do questionário ${ }^{1}$

\begin{tabular}{|c|c|c|c|}
\hline \multicolumn{4}{|c|}{ ESCALAS DO NOSSO QUESTIONÁRIO } \\
\hline \multicolumn{2}{|c|}{ SEÇÃO MOTIVACIONAL } & \multicolumn{2}{|c|}{ SEÇÃO DE ESTRATÉGIAS DE APRENDIZAGEM } \\
\hline ESCALA & SUBESCALA & ESCALA & SUBESCALA \\
\hline \multirow{3}{*}{ VALOR } & Orientação para meta intrínseca & \multirow{3}{*}{ COGNITIVA } & Elaboração \\
\hline & Orientação para meta extrínseca & & \multirow{2}{*}{ Organização } \\
\hline & Valor da tarefa & & \\
\hline \multirow[b]{2}{*}{ EXPECTATIVA } & Percepção de autoeficácia & \multirow[b]{2}{*}{ METACOGNITIVA } & \multirow{2}{*}{$\begin{array}{l}\text { Metacognição e } \\
\text { autorregulação }\end{array}$} \\
\hline & $\begin{array}{c}\text { Crenças sobre o controle da } \\
\text { aprendizagem }\end{array}$ & & \\
\hline \multirow{3}{*}{ AFETO } & \multirow{3}{*}{ Ansiedade frente a provas } & \multirow{3}{*}{$\begin{array}{l}\text { GERENCIAMENTO DE } \\
\text { RECURSOS }\end{array}$} & Gerenciamento do tempo \\
\hline & & & Busca por ajuda \\
\hline & & & Regulação do esforço \\
\hline
\end{tabular}




\section{Resultados}

Foi possível fazer uma análise descritiva de cada turma e gerar uma análise descritiva geral de todas as turmas pesquisadas, osque nos possibilitou discutir os resultados obtidos.

Os dados foram ordenados por subescalas, da seguinte forma: MI (orientação para meta intrínseca); ME (orientação para meta extrínseca); VT (valor da tarefa); CC (crenças de controle); AE (autoeficácia); AP (ansiedade frente a provas); EL (elaboração); OR (organização); AR (autorregulação); GT (gerenciamento do tempo); ER (regulação do esforço); BA (busca por ajuda).

O curso de Engenharia Ambiental da instituição privada, na primeira aplicação, no início do período, apresentou maior e menor resultados globais nas subescalas autoeficácia (AE) e gerenciamento do tempo (GT), 6,5 e 4,43, respectivamente. $O$ mesmo curso, na segunda aplicação (no final do período, antes da última avaliação), apresentou maior e menor resultados globais nas subescalas valor da tarefa (VT) e gerenciamento do tempo (GT), 6,26 e 4,12 nessa ordem. Assim, verificamos que, nos dois momentos, não saber gerenciar o tempo foi o aspecto crítico nessa turma.

Ainda na mesma instituição privada, no curso de Engenharia Elétrica, a primeira aplicação, no início do período, apresentou maior e menor resultados globais nas subescalas valor da tarefa (VT) e gerenciamento de tempo (GT), 6,3 e 4,3, respectivamente. No final do período, na segunda aplicação, antes da última avaliação, apresentaram maior e menor resultados globais as subescalas autoeficácia (AE) e gerenciamento do tempo (GT), 6,39 e 4,56. Verifica-se, portanto, a reincidência de os estudantes não gerirem adequadamente o tempo.

O curso de Matemática da instituição pública, na primeira aplicação, no início do período, apresentou maior e menor resultados globais nas subescalas valor da tarefa (VT) e gerenciamento de tempo (GT) 6,32 e 4,9, respectivamente. Já na segunda aplicação, ou seja, no final do período, antes da última avaliação, apresentou como maior e menor resultados globais as subescalas valor da tarefa (VT) e autorregulação (AR) 6,42 e 4,62, respectivamente. Nesse curso, o valor da tarefa (VT) foi a subescala mais significativa.

É interessante notar que encontramos dois aspectos "não esperados" e comuns às três turmas analisadas: mesmo ao final do semestre, após terem sido submetidos à "maratona" do Cálculo, os estudantes não deixaram de apresentar uma significativa crença em sua capacidade em aprender, além de terem interesse elevado pelos conteúdos de CDI. Esse é um dado importante, pois contraria certo consenso do papel "devastador" que, historicamente, a disciplina CDI causa à autoestima dos alunos. Além disso, contrapõe-se à hipótese de que esses alunos acham os conteúdos próprios de CDI desestimulantes.

Outro aspecto que merece atenção recai nas dificuldades encontradas nas duas aplicações e nas três turmas analisadas, com relação ao gerenciamento do tempo. Estudantes com essa dificuldade podem apresentar desempenho inferior às suas reais capacidades. Bartalo e Guimarães (2008) observam que, em particular, os estudantes precisam se dividir entre o curso superior e o trabalho - situação bastante comum nos cursos noturnos - um elemento poder-se-á tornar determinante para um bom desempenho do estudante. Essa subescala da seção de estratégias de aprendizagem chama nossa atenção e reforça a importância e necessidade de os estudantes serem orientados adequadamente nas estratégias de 
aprendizagem. Boruchovitch (2001), nos alerta que, dentre as principais contribuições da Psicologia Cognitiva para a educação, podemos destacar:

[...] a convicção de que todo aluno pode ser bem-sucedido e autorregulado, a consciência de que "ensinar a aprender" e "aprender a aprender" são projetos pedagógicos difíceis, porém passíveis de serem alcançados, e a crença nas estratégias de aprendizagem como variávelchave para o fortalecimento da capacidade de aprender e de elevar a qualidade do desempenho escolar de alunos. (Boruchovitch, 2001, p. 162)

A dificuldade aqui detectada no gerenciamento do tempo (GT) também foi identificada por Bartalo (2006) em sua pesquisa com estudantes de Ciências Exatas, quando comparados com os de outras áreas.

É importante observar que em todas as aplicações do questionário, as menores escalas apresentadas estavam na seção de estratégias de aprendizagem, e isso reforça a necessidade de adotarmos práticas que estimulem o desenvolvimento de tais estratégias pelos estudantes.

\section{Discussão dos Resultados}

Diante dos resultados mencionados, torna-se necessárias algumas orientações na tentativa de influenciar positivamente as estratégias de estudo adotadas pelos estudantes. Desse modo, apresentamos alguns exemplos que podem servir para redirecionar e potencializar os resultados obtidos em nossa pesquisa.

Larson e Edwards (2005) reeditaram o livro-texto "Cálculo com Aplicações", orientando os estudantes a seguir um roteiro didático, além de apontar estratégias de estudo, bastante apropriadas como intervenção para a aprendizagem dessa disciplina.

Nesse livro (Larson; Edwards, 2005), os autores apresentam seus conteúdos de modo que nos possibilite identificar a presença das bases teóricas do nosso questionário MSLQ, do qual apresentaremos alguns exemplos, conforme a seguir.

Na seção de estratégias de aprendizagem, em todas as turmas analisadas, concentraram-se os menores resultados, que é um olhar diferenciado para a aprendizagem dos estudantes, um aspecto também constatado na obra de Larson e Edwards (2005). Ainda nesse livro, eles apresentam, inicialmente, um plano de estudo com vistas a orientar os estudantes para utilização de estratégias adequadas. Ao longo dos oito capítulos, os autores iniciam apontando para as estratégias de como obter sucesso com relação ao objeto de estudo matemático a ser aprendido, e enfatizam o que será aprendido e o porquê da necessidade de aprender.

Por exemplo, no capítulo 1, intitulado "Funções, Gráfico e Limites" possui as seguintes orientações: 
Estratégias para o sucesso.

O que você vai aprender:

$>$ Como plotar pontos no plano cartesiano e determinar a distância entre dois pontos;

$>$ Como plotar o gráfico de uma equação e determinar as interseções com os eixos x e y;

$>$ Com escrever equações de retas e plotar retas;

$>$ Como calcular os valores de funções, simplificar e determinar funções inversas;

$>$ Como determinar o limite de uma função e discutir a continuidade de vários tipos de funções;

Por que você precisa aprender:

As funções têm muitas aplicações práticas, como demonstram os exemplos abaixo, que representam uma pequena amostra das aplicações apresentadas nos exercícios.

$>$ Índice Dow Jones, exercícios 35 e 36 (exercícios 1.1);

$>$ Análise de Equilíbrio, exercícios 63 e 68 (exercícios 1.2);

> Depreciação Linear, exercícios 86 e 87 (exercícios 1.3);

> Função Demanda, exercícios 69 (exercícios 1.4);

$>$ Equilíbrio de Mercado, exercício 72 exercícios 1.5).

(Larson; Edwards, 2005, p.33).

A subescala que envolve esse tipo de abordagem é a Organização (OR), pois envolve as tentativas de organizar e sintetizar o que precisa ser aprendido na disciplina.

A fragilidade apresentada por todas as turmas pesquisadas foi a deficiência em gerir bem o tempo. Larson e Edwards (2005), ao apresentarem o plano de estudo, descrevem uma forma eficiente de gerir adequadamente o tempo de estudo, conforme descrevem:

O sucesso nos estudos de matemática depende de uma participação ativa, tanto em classe como fora da classe. Como os tópicos expostos ao aluno dependem de assuntos estudados anteriormente, é importante que ele mantenha a matéria em dia e formule um plano de estudo. (Larson; Edwards, 2005, p. 18)

Larson e Edwards (2005), ao apresentarem os exemplos, os resolvem graficamente, algebricamente e numericamente. Posteriormente, apresentam uma estratégia autorregulatória, ou seja, após serem apresentados os exemplos como ferramenta de estudo, os estudantes são solicitados resolver novos problemas que irão ajudá-los a reforçar a apropriação dos conceitos.

Outra estratégia autorregulatória é apresentada no mesmo livro, ao final de cada um dos oito capítulos, em que se expõe um resumo do capítulo e se descrevem novamente, estratégias de estudo.

São apresentados, também, os "exercícios de aquecimento" ao longo de cada capítulo para permitir que o estudante possa rever e praticar os conhecimentos adquiridos anteriormente.

Todos os cursos pesquisados apresentaram um alto índice na escala valor da tarefa (VT), permitindo-nos destacar alguns exemplos que podem potencializar o interesse que dão à 
disciplina de CDI. Vejamos algumas situações-problemas com que os mesmos autores corroboram em destacá-los em determinados contextos, conforme as Figuras 1, 2 e 3.

O fato de a motivação no contexto escolar ser influenciada pelos tipos de tarefas propostas, pelo comportamento e métodos de ensino do professor, tanto coloca o docente em uma posição privilegiada para intervir como incumbe-lhe responsabilidade nesse processo, caso haja fracasso. Para a Psicologia Cognitiva, a inteligência e a capacidade intelectual não são por si só suficientes para explicar o sucesso ou o fracasso escolar do estudante. O domínio e o uso adequado das estratégias, como a de gerenciamento de tempo, por exemplo, favorecem a aprendizagem dos estudantes.

55. Demanda Quando um atacadista vende um produto por um preço unitário de $\mathrm{R} \$$ 32,00 , consegue vender 750 unidades por semana. Quando o preço unitário é aumentado em $R \$ 5,00$, as vendas caem para 700 unidades por semana.

(a) Escreva uma equação para o número de unidades vendidas $\mathrm{x}$ como uma função linear do preço $p$.

(b) Interpolação Linear Estime o número de unidades vendidas ao preço unitário de $\mathrm{R} \$ 34,50$.

(c) Extrapolação Linear Estime o número de unidades vendidas ao preço unitário de $\mathrm{R} \$ 42,00$.

Figura 1. Demanda

Fonte: Larson, Edwards, 2005, p. 103

72. Taxa de Juros dos Cartões de Crédito A taxa média anual de juros $r$ (em forma percentual) cobrados pelos cartões de crédito nos Estados Unidos entre 1993 e 1999 pode ser modelada pela função:

$$
\begin{array}{r}
r=\sqrt{-0, \emptyset t^{4}+0, \varnothing t^{3}+5,8 t^{2}-\emptyset, 8 t+437,8}, \text { onde } \mathrm{t}=3 \text { representa } 1993 . \\
\text { (Fonte: Federal Reserve Bulletini) }
\end{array}
$$

(a) Determine a derivada dessa função. Quais foram as regras de derivação que você usou?

(b) Use um programa de plotagem para traçar o gráfico da derivada no intervalo .

(c) Use a função trace para determinar os anos nos quais a taxa de juros estava variando mais rapidamente.

(d) Use a função trace para determinar os anos nos quais a taxa de juros estava variando mais lentamente. 


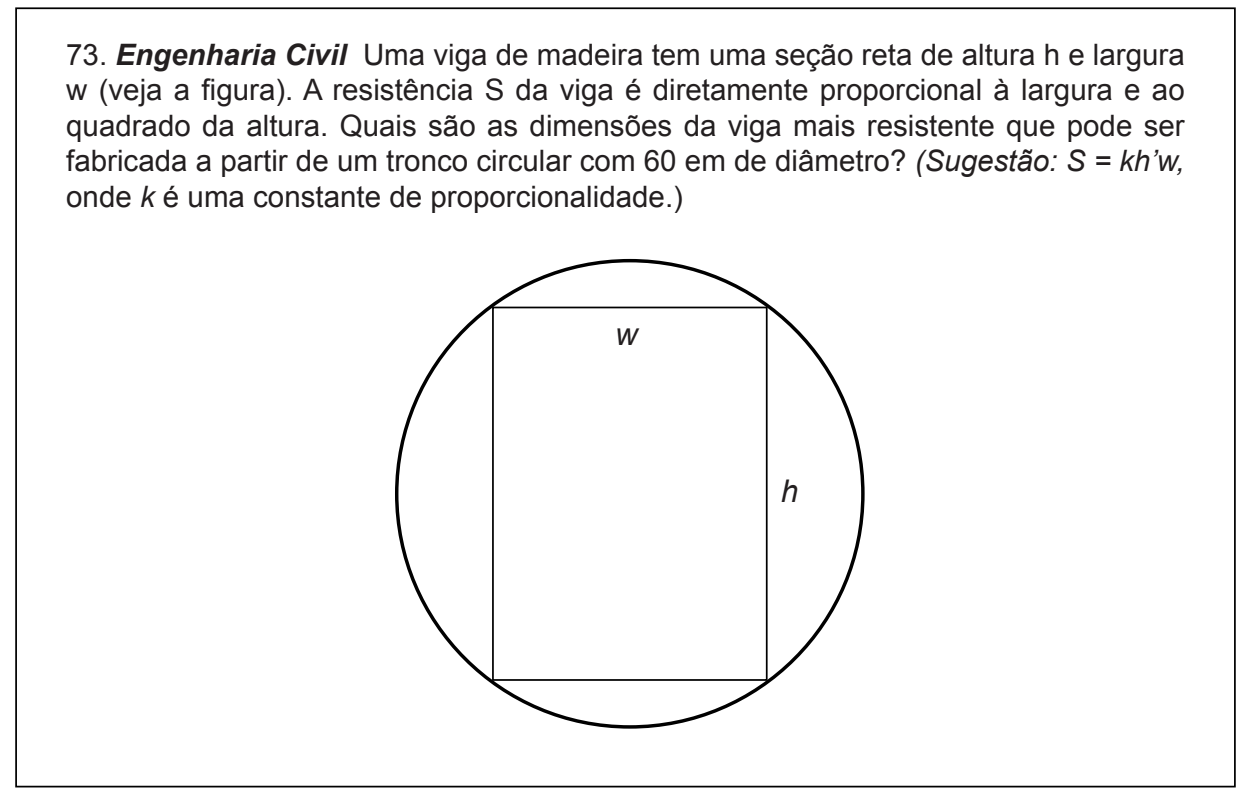

Figura 3: Engenharia Civil

Fonte: Larson, Edwards, 2005, p. 223

\section{Conclusão}

A aplicação e a análise dos questionários permitiram-nos traçar um perfil das turmas analisadas, de modo que pudéssemos verificar quais suas potencialidades e fragilidades, de forma geral. Quando traçamos o perfil da turma, apareceram indícios da necessidade de haver intervenção do professor na classe. Acreditamos que com esses resultados, possibilitou-se repensar e buscar sobre outras formas de ensinar e de aprender mais eficientes. Acreditamos ainda que os professores podem potencializar os resultados, ora com estratégias de ensino voltadas para as fragilidades da turma e/ou de cada estudante, ora com estratégias de aprendizagem focadas nos pontos fortes do discente (orientando sua turma, inclusive, para lidar com suas fragilidades). Desse modo, alcançamos nosso objetivo, quando apresentamos aos professores da disciplina, subsídios que permitem potencializar ou redirecionar esses parâmetros, tendo em vista que os estudantes são os sujeitos em que, naturalmente, estão voltados para a aprendizagem.

A trajetória dessa pesquisa reforçou o caráter multifacetado das questões levantadas pelo ensino de CDI. Entendemos que se faz necessário que os profissionais da Matemática sejam estimulados a participar de projetos de formação continuada para professores, com foco tanto nos aspectos específicos da área como nos de outras, (por exemplo, a Psicologia Cognitiva), no sentido de incitar reflexão, discussão e ação em prol do processo de ensino e de aprendizagem, além de aprimorar sua prática docente. Esse contato não se restringe aos professores de CDI, como constatamos em Rezende (2003), cujas questões já perpassam o conhecimento do Ensino Fundamental e Médio.

Será importante destacar que as análises aqui realizadas de forma coletiva também podem, e devem, ser realizadas de forma individual, de modo que o estudante possa receber orientações para redirecionar e/ou potencializar os valores das escalas apresentadas, em virtude de suas respostas ao questionário.

Apesar de entendermos que esse trabalho tem o objetivo de contribuir para práticas 
docente e discente, não é de modo algum "uma receita" ou "um método" de ensino e de aprendizagem. Pelo contrário, temos a ciência das limitações (ou restrições) de nossa proposta, porque se deve levar em conta a diversidade existente em cada grupo, ou indivíduo, pois todos estão sob o julgo das variadas dimensões que os compõem, como a social, a histórica, a econômica, a individual, a cognitiva, a psíquica, entre outras. Além disso, o ato de ensinar, assim como o de aprender, tem de ser um processo dinâmico e deve, necessariamente, se adequar às mudanças que advêm do meio em que a educação se encontra.

Por fim, vale ainda ressaltar que os aspectos motivacionais são fundamentais em qualquer nível de ensino, conforme constatamos a partir da investigação bibliográfica realizada. Na prática, nosso testemunho também corrobora para a constatação de que os aspectos motivacionais são elementos significativos no processo de aprendizagem dos estudantes, além de atentar para o aspecto da autoestima dos sujeitos envolvidos nesse processo. A dimensão da autoestima não foi foco de nossa investigação, mas possibilita um ponto de partida para futuras pesquisas, inclusive concomitantemente, com utilização do perfil motivacional e de estratégias de aprendizagem. 


\section{Nota}

1 O questionário completo encontra-se na Dissertação de Mestrado Profissional em Educação Matemática, defendida em 2011, por Odileia da Silva Rosa, Universidade Severino Sombra-RJ.

\section{Referências}

Bartalo, L. (2006) Mensuração de estratégias de estudo e aprendizagem de alunos universitários: learning and study strategies inventory (LASSI) adaptação e validação para o Brasil. Tese de doutoramento não-publicada, Universidade Estadual Paulista Julio de Mesquita Filho, Marília, Brasil.

Barufi, M.C. (1999) A construção/negociação de significados no curso universitário inicial de Cálculo Diferencial e integral. Tese de doutoramento não-publicada, Universidade do Estado de São Paulo, São Paulo, Brasil.

Genari, C.H.M. (2006) Motivação no contexto escolar e desempenho acadêmico. Dissertação de mestrado não-publicada, Universidade Estadual de Campinas, Campinas, Brasil.

Guimarães, S.E.R. (2003) Avaliação do estilo motivacional do professor: adaptação e validação de um instrumento. Tese de doutoramento não-publicada, Universidade Estadual de Campinas, Campinas, Brasil.

Larson, R.; Edwards, B. H. Cálculo com aplicações. Trad. Ronaldo Sérgio de Biasi. 6. ed. Rio de Janeiro: LTC, 2005.

Lens, W.; Matos, L.; Vansteenkiste, M. (2008) Professores como fonte de motivação dos alunos: O quê e o porquê da aprendizagem do aluno. Educação, 31, 17-20.

Locatelli, A. C. D. (2004) A perspectiva de tempo futuro como um aspecto da motivação do adolescente na escola. Dissertação de mestrado não-publicada, Universidade Estadual de Londrina, Londrina, Brasil.

Pintrich, P.R.; Smith, D.A.F., Garcia, T.; McKeachie, W.J. (1991). A Manual for the use of the motivated strategies for learning questionnaire (MSLQ). Ann Arbor, Mich: University of Michigan.

Rosa, O. S. (2011) Aspectos Motivacionais do Cálculo Diferencial e Integral. Dissertação de Mestrado Profissional em Educação Matemática, Universidade Severino Sombra, Vassouras-RJ, Brasil.

Ruiz, V. M. (2005) Aprendizagem em universitários: variáveis motivacionais. Tese de doutoramento não-publicada, Pontifícia Universidade Católica, Campinas, Brasil.

Souza, L.F.N.I. (2010) Estratégias de aprendizagem e fatores motivacionais relacionados. Educ. rev., n. 36, p. 95-107. doi: 10.1590/S0104-40602010000100008.

Zenorini, R. P. C. (2007). Estudos para a construção de uma escala de avaliação da motivação para aprendizagem - EMA. Tese de doutoramento não-publicada, Universidade São Francisco, Itatiba, Brasil. 